\title{
Substrain Comparison of Genetically Hypertensive Rats Using DNA Fingerprinting, and Genetic Analysis of Blood Pressure in the Inbred Rats
}

\author{
Tomohiro Katsuya, Jitsuo Higaki, Tetsuro Miki, Jun \\ Nakura, Hiroshi Ikegami, Ryuichi Morishita, \\ Masahiro Nagano, Koichi Higashimori, Fumiaki \\ Nakamura, Hiroshi Mikami and Toshio Ogihara \\ Department of Geriatric Medicine, Osaka University \\ Medical School, Osaka 553
}

\begin{abstract}
Katsuya, T., Higaki, J., Miki, T., Nakura, J., Inegami, H., Morishita, R., Nagano, M., Higashimori, K., Nakamura, F., Mikami, H. and Oginara, T. Substrain Comparison of Genetically Hypertensive Rats Using DNA Fingerprinting, and Genetic Analysis of Blood Pressure in the Inbred Rats. Tohoku J. Exp. Med., 1991, 165 (4), 253-260 — Using DNA fingerprinting, genetic heterogeneity or homogeneity was studied between substrains of spontaneously hypertensive rats (SHR) and Wistar-Kyoto (WKY) rats maintained in Japan. Using human myoglobin minisatellite 33.15 as a probe, we did not detect any inter- or intrasubstrain genetic heterogeneities in HinfI digests of SHR or WKY rat DNA. However, analysis of Sau3AI digests of rat DNA using mouse C-6 gene as a probe revealed intra-substrain heterogeneity of 1-2 DNA bands in one of the WKY rat substrains. In the other substrains of SHR and WKY rats, there existed no intra-substrain heterogeneities, but several inter-substrain heterogeneities were observed in both SHR and WKY rats. In another experiment using the inbred substrains of SHR and WKY rats which have been confirmed as genetically homogeneous, we produced $\mathrm{F}_{1}$ and $\mathrm{F}_{2}$ rats, and biometrically analyzed their systolic blood pressure. The results suggested that there may be 1-4 dominant antihypertensinogenic genes with high heritability of 0.6-0.7._— hypertension; gene; spontaneously hypertensive rat; Wistar-Kyoto rat; DNA fingerprinting
\end{abstract}

Since the spontaneously hypertensive rat (SHR) has been developed by Okamoto and Aoki (1963), it has become a widely studied model of human essential hypertension. The SHR and its normotensive control of Wistar-Kyoto (WKY) rat were first introduced to National Institute of Health, USA, and then distributed to scientific farms world-wide. Many colonies of substrains of SHR or WKY rats are now maintained, but intra-colony or inter-colony variations should have been evolved among them (Yamori 1989). Classical mating experiments with SHR and WKY rats have been performed for the genetic analysis of Received July 11, 1991; revision accepted for publication October 17, 1991. 
hypertension by several research groups (Tanase et al. 1970; Yen et al. 1974; Judy et al. 1979; Harrap 1986; Kurtz et al. 1990). However, the results are rather controversial, probably due to lack of a technical skill in the measurement of blood pressure or possible genetic heterogeneity of these strains. Recent progress in molecular biology has enabled us to evaluate directly the genetic homogeneity using DNA fingerprint analysis. In the present study, we investigated the inter- and intra-strain variations of SHR and WKY rats at gene level. In addition, biometric genetic analysis of hypertension was performed by crossing inbred substrains of SHR and WKY rats whose genetic homogeneity had been confirmed by DNA fingerprinting.

\section{Materials and Methods}

The substrains of SHR and WKY rats were kind gifts from by Dr. Tanase, Laboratory Animal Science and Toxicology Laboratories, Sankyo Co. Ltd., Shizuoka. Other sets of SHR and WKY rats were obtained from closed colonies at Charles River Japan, Inc., Atsugi, Kanagawa, and also from Vendor "A", and Vendor "B" in Japan. The SHR and WKY rats maintained at Charles River Laboratories, Inc., Wilmington, Mass., USA, and the WKY rats maintained at the University of Heidelberg, Heidelberg, Germany, were also obtained for the international standardization of substrains.

\section{DNA fingerprint analysis}

High molecular weight DNA was extracted from rat liver by the standard phenol/ chloroform extraction method (Sambrook et al. 1989). DNA fingerprint analysis was performed after digestion of rat DNAs with HinfI or Sau3AI by Southern hybridization method (Sambrook et al. 1989) using human myoglobin 33.15 (Jeffreys et al. 1985) or mouse C-6 minisatellite gene probes (Kominami et al. unpublished) which had been isolated from a mouse genomic library by hybridization with the $33 \mathrm{bp}$ repeat probe from pAV33.7 (Jeffreys et al. 1985), respectively. Digested samples were run in $0.8 \%$ agarose gels and blotted on nylon-membrane filter (Hybond $\mathrm{N}+$, Amersham). Each of the DNA probes were radiolabeled with $\left[{ }^{32} \mathrm{P}\right] \mathrm{dCTP}$ by a random priming method (Feinberg and Vogelstein 1984). Blots were hybridized with the radiolabeled probes in $6 \times$ SSC, $5 \times$ Denhart's solution and $100 \mu \mathrm{g} / \mathrm{ml}$ salmon sperm DNA at $65^{\circ} \mathrm{C}$ for at least $12 \mathrm{hr}$. Filters were washed at room temperature with $2 \times \mathrm{SSC}$, at $65^{\circ} \mathrm{C}$ with $2 \times \mathrm{SSC}-0.5 \%$ SDS for $10 \mathrm{~min}$ and then at $65^{\circ} \mathrm{C}$ with $0.1 \times$ SSC- $0.5 \%$ SDS for 10 min. Washed blots were exposed to X-ray film (Kodak $\mathrm{XS}-1$ ) at $-70^{\circ} \mathrm{C}$ for 1-3 days. Minisatellite gene 33.15 was kindly supplied by Dr. Jeffreys, Department of Genetics, University of Leicester, Leicester, England, and C-6 gene was a kind gift from Dr. Kominami, Department of Biochemistry, Medical School of Niigata University, Niigata.

\section{Cross analysis}

SHR and WKY rats obtained from Charles River Japan, Inc. were used for cross analysis, because these substrains had been confirmed to be inbred and genetically homologous to the other major substrains. Crosses were made between 10 male SHRs and 10 female WKY rats, and these $F_{1}$ hybrids were intercrossed for the study of $F_{2}$ segregating generation. All rats were housed under identical environmental conditions at the temperature of $23 \pm+1^{\circ} \mathrm{C}$ (mean \pm S.D.) and the humidity of $55 \pm 5 \%$, and were fed commercial pellet CE-2 supplied from Japan Clea Co., Ltd., Tokyo. Tap water and food were provided ad libitum. Systolic blood pressure was measured by a tail plethysmographic technique, when the rats were twelve weeks old. An average of 2 determinations on 2 different days was 
taken as the systolic blood pressure.

All studies were performed with the permission of Ethical Committee of Animal Research, Osaka University Medical School. Data analysis were performed by the method of Festing (1979). The degree of genetic determination $\left(\mathrm{d}^{2}\right)$ of the systolic blood pressure in SHR was estimated by the formula: $d^{2}=\left(V_{F 2}-V_{F 1}\right) / V_{F 2}$, where $V_{F 2}$ and $V_{F 1}$ are variances of systolic blood pressure of each hybrid. Since the data on the backcrosses are not available, the number of loci related to systolic blood pressure was estimated by a modified formula: $n=\left(P_{1}-P_{2}\right)^{2} / 8\left(V_{F 2}-F_{v 1}\right)$, where $P_{1}$ and $P_{2}$ are the parental means. Because logarithmic transformation of blood pressure did not affect the results, only the untransformed data were presented.

\section{Results}

Strain comparison

The DNA fingerprint patterns of SHR and WKY rats from Sankyo Co., Ltd. using 33.15 gene as a probe resemble each other closely as shown in Fig. 1, and the result is compatible with the fact that SHR was originally derived from WKY rat. Fig. 1 also showed the intra-substrain homogeneity in SHR and WKY maintained

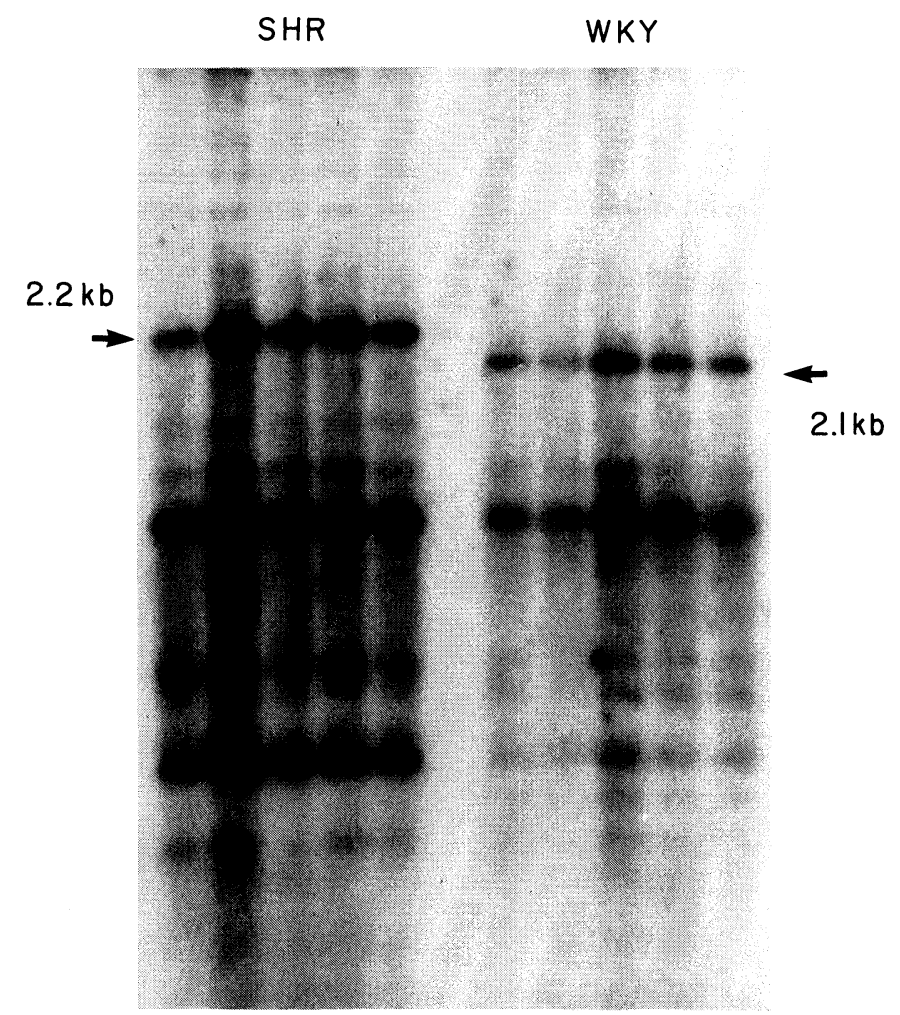

Fig. 1. DNA fingerprints of SHR $(n=5)$ and WKY $(n=5)$ rats from Sankyo Co., Ltd. Each lane contains a sample DNA that was digested by HinfI, electrophoresed, blotted, and hybridized with human minisatellite gene 33.15 probe. 


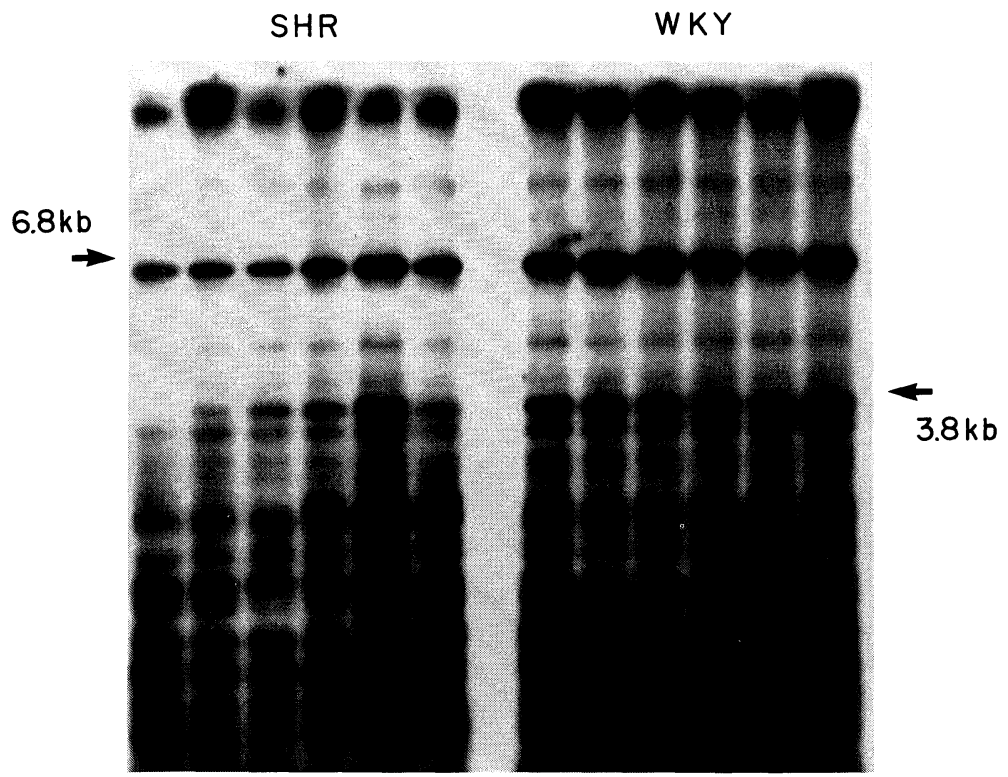

Fig. 2. DNA fingerprints of SHR $(n=6)$ and WKY $(n=6)$ rats from Vendor A. Each lane contains a sample DNA that was digested by Sau3AI, electrophoresed, blotted, and hybridized with mouse minisatellite gene C-6 probe.

\begin{tabular}{|c|c|c|c|c|}
\hline colony & 1 & 2 & 3 & 4 \\
\hline & S W & S W & $\mathrm{S} W$ & S W \\
\hline $\begin{array}{l}\mathrm{C}-6 \\
\text { Sau } 3 \mathrm{AI}\end{array}$ & & & $x(0$ & 0 (1) \\
\hline $\begin{array}{c}33.15 \\
\text { Hinfl }\end{array}$ & & & & \\
\hline
\end{tabular}

\begin{tabular}{|c|c|c|c|c|c|c|}
\hline colony & 1 & 2 & 3 & 4 & 5 & 6 \\
\hline & $\mathrm{S} \quad \mathrm{W}$ & $\mathrm{S} \quad \mathrm{W}$ & $S W$ & S W & 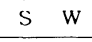 & S W \\
\hline $\begin{array}{l}\text { C-6 } \\
\text { Sau } 3 A I\end{array}$ & $a b$ & $a b$ & (c) $d$ & a e & $a b$ & b \\
\hline $\begin{array}{l}33.15 \\
H i n f I\end{array}$ & $f g$ & f $g$ & f $g$ & f $g$ & & \\
\hline
\end{tabular}

Fig. 3. Results of intra- and inter-substrain variation by DNA fingerprints. $\bigcirc$, genetically homogeneous within substrain ; $\times$, genetically heterogeneous within substrain ; ( ), intra-substrain homogeneity with inter-substrain variations. Alphabets a-g mean unique patterns of DNA fingerprints. a : $16.0,6.8,4.8,4.3,3.8,3.5,3.2,3.0,2.9,2.6,2.4$ kb. b : $16.0,9.4,6.8,4.8,4.3,3.8,3.5,3.2,3.0,2.9,2.6,2.4 \mathrm{~kb}$. c : $16.0,6.8,3.5,3.2,3.0$, $2.9,2.6,2.4 \mathrm{~kb} . \quad \mathrm{d}: 16.0,9.4,6.8,3.8,3.5,3.2,3.0,2.9,2.6,2.4 \mathrm{~kb} . \quad$ e : $16.0,9.4,6.8,3.8$, $3.0,2.9,2.6,2.4 \mathrm{~kb} . \quad \mathrm{f}: 4.6,3.5,2.2,1.8,1.6,1.5,1.2,1.1 \mathrm{~kb} . \quad \mathrm{g}: 4.6,3.5,2.1,1.6,1.5$, $1.2,1.1 \mathrm{~kb}$. 1, Laboratory Animal Science and Toxicology Laboratories, Sankyo Co., Ltd.; 2, Charles River Japan Inc.; 3, Vendor A ; 4, Vendor B ; 5, Charles River Laboratories, USA. ; 6, Heidelberg University, Germany. S, SHR ; W, WKY. 


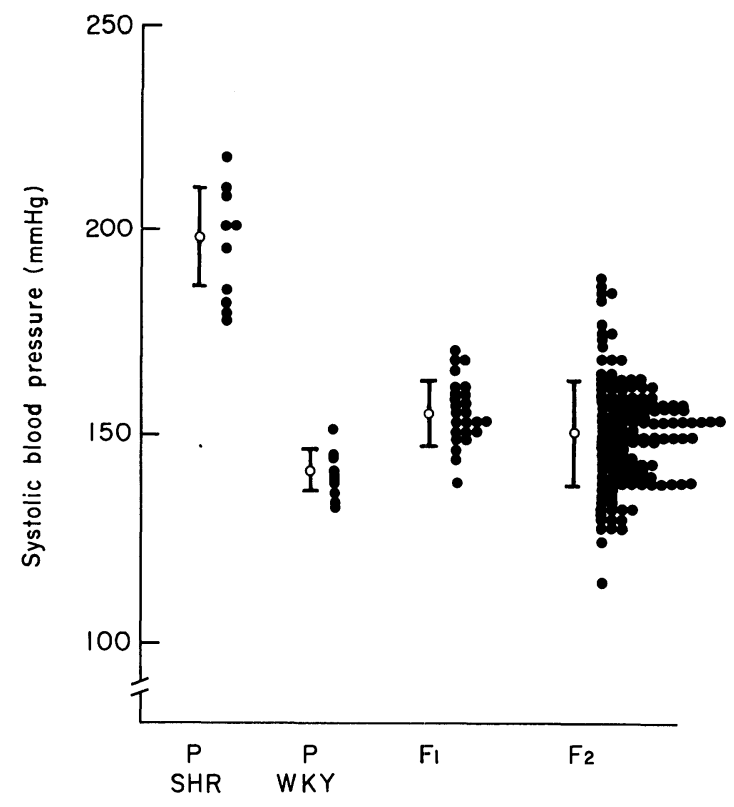

Fig. 4. The distribution of systolic blood pressure at 12 weeks after birth in all male generations used for cross analysis between SHR and WKY rats.

TABLE 1. Systolic blood pressure of each generation in cross between spontaneously hypertensive rat and Wistar-Kyoto rat

\begin{tabular}{lccccc}
\hline & \multicolumn{2}{c}{ Male } & & \multicolumn{2}{c}{ Female } \\
\cline { 2 - 3 } \cline { 5 - 6 } & $\mathrm{mmHg}$ & $(\mathrm{n})$ & & $\mathrm{mmHg}$ & $(\mathrm{n})$ \\
\hline SHR & $197 \pm 12$ & $(10)$ & & $160 \pm 5.6$ & $(10)$ \\
WKY & $140 \pm 5.4$ & $(10)$ & & $129 \pm 5.0$ & $(10)$ \\
$\mathrm{F}_{1}$ & $154 \pm 8.0$ & $(25)$ & & $141 \pm 7.0$ & $(25)$ \\
$\mathrm{F}_{2}$ & $149 \pm 13$ & $(150)$ & & $141 \pm 13$ & $(99)$ \\
\hline
\end{tabular}

Each value is mean \pm s.D.

at this farm. Using 33.15 minisatellite gene as a probe after HinfI digestion of sample DNA, no genetic heterogeneity was detected in any of substrains of SHR and WKY rats. Intra-substrain heterogeneity which was indicated by lack of 4.8, 4.3 or $3.8 \mathrm{~kb}$ bands in some SHR rats from Vendor A was detected with C-6 probe as shown in Fig. 2, while WKY rats showed genetic homogeneity. The results of substrain comparisons are presented in Fig. 3. C-6 probe revealed intra-substrain variation in SHR rats from Vendor $\mathrm{A}$ and inter-substrain variation in SHR or WKY from Vendor A and Vendor B. 


\section{Biometric genetic analysis}

Fig. 4 and Table 1 show the distribution of systolic blood pressure at 12 weeks after birth in all generations used for cross analysis between SHR and WKY rats. The mean systolic blood pressure of $\mathrm{F}_{1}$ is between those of parental SHR and WKY rats; however, the value is lower than the median of both parental blood pressures. The mean systolic blood pressure of $\mathrm{F}_{2}$ generation is similar to that of $\mathrm{F}_{1}$ generation with the variance of $\mathrm{F}_{2}$ generation being greater. The systolic blood pressure of female rats are apparently lower than those of male rats in all generations. The degree of genetic determination $\left(\mathrm{d}^{2}\right)$ of systolic blood pressure in SHR are estimated as $0.621 \pm 0.125$ (s.E.) in male rats and $0.710 \pm 0.09$ in female rats. The number of effective loci or blocks of loci estimated using the modified formula is between one and four.

\section{Discussion}

Because the incidence of hypertension in SHR is $100 \%$, the investigation of the gene(s) involved in the development of hypertension is quite important. Traditionally, by classical crosses between SHR and WKY rat, many researchers tried genetic biometric assays to determine the molecular etiology of hypertenison. However, their results are rather controversial, except that SHR may have one or more hypertensinogenic gene(s) (Tanase et al. 1970; Yen et al. 1974 ; Judy et al. 1979 ; Harrap 1986; Kurtz et al. 1990). Possible reason for the controversies may be genetic heterogeneity of the experimental rats, because the researchers use various SHR and WKY colonies in their experiments. Recent genetic survey using some biochemical markers proved that there may be genetic heterogeneities between substrains of SHR and WKY rats (Yamori 1989). More recently, the molecular evidence of genetic heterogeneity of WKY rats in European and American stocks was directly shown by DNA fingerprinting (Samani et al. 1989 ; Kurtz et al. 1989). Then, we first investigated the possible intra- and intersubstrain gene variations in substrains of SHR and WKY rats maintained in major Japanese suppliers. Furthermore, for an international standardization of these substrains, typical American colony (SHR/CRL, WKY/CRL) and European WKY colony (WKY/Heidelberg) were also studied.

The result first shown that the DNA fingerprint patterns of SHR and WKY resemble each other closely, indicating that the strain of SHR was originally derived from WKY. The present study shows that, at least using 33.15 gene probe, we found no intra- and inter-substrain variations in all SHR and WKY colonies. However, using mouse C-6 probe, intra-substrain heterogeneity was detected in SHR from one institute. Furthermore, the DNA fingerprint patterns were different between substrains of SHR and WKY. These results also suggest that the C-6 probe is more useful to detect the strict genetic heterogeneities of SHR or WKY. However, the significance of these trifling genetic heterogeneities 
is not established at all, and we think these levels of genetic heterogeneity may be permissible for an ordinary study of hypertension.

However, in the present study, we have selected the substrains of SHR and WKY from Charles River Japan for the cross mating experiment. We considered that they are genetically identical with Japanese Sankyo's colony and major American and European colonies, for which results of genetic analysis have been reported in detail. The cross experiment in the present study with male SHR and female WKY showed that the heritability of systolic blood pressure is quite high (over $60 \%$ ). Average systolic blood pressure of $\mathrm{F}_{1}$ and $\mathrm{F}_{2}$ are apparently lower than median values of the systolic blood pressure of the parent SHR and WKY. These results are compatible with those reported by Kurtz et al. (1990), concluding that SHR may have several dominant anti-hypertensinogenic alleles. It is also shown that systolic blood pressure can be a good genetic marker instead of mean blood pressure in these rats. Furthermore, the fact that blood pressure of female rats were significantly lower than that of male rats in all generations suggests that the hypertension-related genes have a maternal effect.

The more detailed genetic biometric analysis can not be performed because we did not make backcross generations. However, we conclude that our SHR is genetically homogeneous with the other substrains of SHRs from major suppliers in the world and may have 1-4 genes that suppress blood pressure in dominant fashion with high heritability.

\section{Acknowledgment}

We thank Dr. J. Howard (Whitehead Institute, Cambridge, MA, USA) for supplying the DNAs of the SHRs and WKY rats from Charles River Laboratories, USA, and Heidelberg University, Germany.

\section{References}

1) Feinberg, A.P. \& Vogelstein, B. (1984) Addendum: A technique for radiolabeling DNA restriction endonuclease fragment to high specific activity. Anal. Biochem., 137, 266-267.

2) Festing, M.F.W. (1979) Inbred Strains in Biomedical Research, The Macmillan Press Ltd., Basingstoke, Hampshire, U.K.

3) Harrap, S.B. (1986) Genetic analysis of blood pressure and sodium balance in spontaneously hypertensive rats. Hypertension, 8, 572-582.

4) Jeffreys, A.J., Wilson, V. \& Thein, S.L. (1985) Hypervariable 'minisatellite' regions in human DNA. Nature, 314, 67-73.

5) Judy, W.V., Watanabe, A.M., Murphy, W.R., Aprison, B.S. \& Yu, P.L. (1979) Sympathetic nerve activity and blood pressure in normotensive backcross rats genetically related to the spontaneously hypertensive rat. Hypertension, 1, 598-604.

6) Kurtz, T.W., Montano, M., Chan, L. \& Kabra, P. (1989) Molecular evidence of genetic heterogeneity in Wistar-Kyoto rats : Implications for research with the spontaneously hypertensive rat. Hypertension, 13, 188-192.

7) Kurtz, T.W., Casto, R., Simonet, L. \& Printz, M.P. (1990) Biometric genetic analysis of blood pressure in the spontaneously hypertensive rat. Hypertension, 16, 718-724.

8) Okamoto, K. \& Aoki, K. (1963) Development of a strain of spontaneously hyperten- 
sive rats. Jpn. Circ. J., 30, 282-293.

9) Samani, M.J., Swales, J.D., Jeffreys, A.J., Morton, D.B., Naftilan, A.J., Lindpainter, K., Ganten, D. \& Brmmar, W.J. (1989) DNA fingerprinting of spontaneously hypertensive and Wistar-Kyoto rats: Implications for hypertension research. J. Hypertens., 7, 809-816.

10) Sambrook, J., Fritsch, E.F. \& Maniatis, T. (1989) Molecular Cloning, A Laboratory Manual, 2nd ed., Cold Spring Harbor Laboratory Press, Cold Spring Harbor.

11) Tanase, H., Suzuki, Y., Ooshima, A., Yamori, Y. \& Okamoto, K. (1970) Genetic analysis of blood pressure in spontaneously hypertensive rats. JPn. Circ. J., 34, 11971212.

12) Yamori, Y. (1989) Predictive and preventive pathology of cardiovascular diseases. Acta Pathol. Jpn., 39, 683-705.

13) Yen, T.T., Yu, P., Roder, H. \& Willard, P.W. (1974) A genetic study of hypertension in Okamoto-Aoki spontaneously hypertensive rats. Heredity, 33, 309-316. 